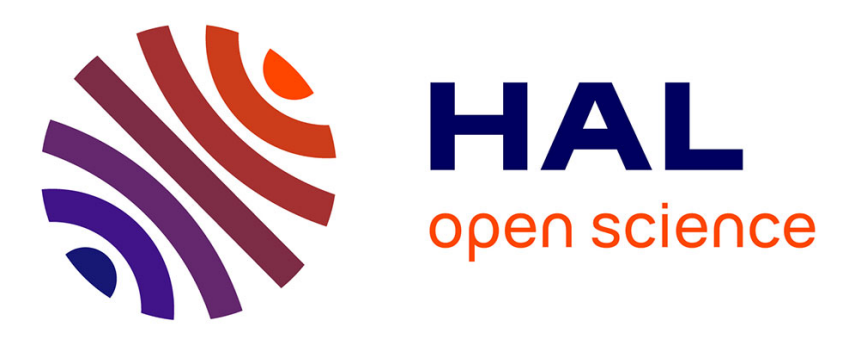

\title{
Evolution of flax cell wall ultrastructure and mechanical properties during the retting step
}

\author{
Alain Bourmaud, David Siniscalco, Loic Foucat, Camille Goudenhooft, Xavier \\ Falourd, Bruno Pontoire, Olivier Arnould, Johnny Beaugrand, Christophe \\ Baley
}

\section{To cite this version:}

Alain Bourmaud, David Siniscalco, Loic Foucat, Camille Goudenhooft, Xavier Falourd, et al.. Evolution of flax cell wall ultrastructure and mechanical properties during the retting step. Carbohydrate Polymers, 2019, 206, pp.48 - 56. 10.1016/j.carbpol.2018.10.065 . hal-01937778

\section{HAL Id: hal-01937778 https://hal.science/hal-01937778}

Submitted on 28 Nov 2018

HAL is a multi-disciplinary open access archive for the deposit and dissemination of scientific research documents, whether they are published or not. The documents may come from teaching and research institutions in France or abroad, or from public or private research centers.
L'archive ouverte pluridisciplinaire HAL, est destinée au dépôt et à la diffusion de documents scientifiques de niveau recherche, publiés ou non, émanant des établissements d'enseignement et de recherche français ou étrangers, des laboratoires publics ou privés. 


\title{
Evolution of flax cell wall ultrastructure and mechanical properties during the retting step
}

\author{
Alain Bourmaud ${ }^{\mathrm{a}, *}$, David Siniscalco ${ }^{\mathrm{a}}$, Loïc Foucat ${ }^{\mathrm{b}}$, Camille Goudenhooft ${ }^{\mathrm{a}}$, Xavier Falourd ${ }^{\mathrm{b}}$, \\ Bruno Pontoire $^{\mathrm{b}}$, Olivier Arnould ${ }^{\mathrm{c}}$, Johnny Beaugrand ${ }^{\mathrm{b}}$, Christophe Baley ${ }^{\mathrm{a}}$ \\ ${ }^{a} I R D L$, Université Européenne Bretagne, CNRS, UMR 6027, Lorient, France \\ ${ }^{\mathrm{b}}$ UR1 268 Biopolymères Interactions Assemblages, INRA, Nantes, France \\ ${ }^{\mathrm{c}}$ LMGC, Université de Montpellier, CNRS, UMR 5508, Montpellier, France
}

\begin{abstract}
A B S T R A C T
Flax retting is a major bioprocess in the cultivation and extraction cycle of flax fibres. The aim of the present study is to improve the understanding of the evolution of fibre properties and ultrastructure caused by this process at the plant cell wall scale. Initially, investigations of the mechanical performances of the flax cell walls by Atomic Force Microscopy (AFM) in Peak Force mode revealed a significant increase $(+33 \%)$ in the cell wall indentation modulus with retting time. Two complementary structural studies are presented here, namely using X-Ray Diffraction (XRD) and solid state Nuclear Magnetic Resonance (NMR). An estimation of the cellulose crystallinity index by XRD measurements, confirmed by NMR, shows an increase of $8 \%$ in crystallinity with retting mainly due to the disappearance of amorphous polymer. In addition, NMR investigations show a com-paction of inaccessible cell wall polymers, combined with an increase in the relaxation times of the C4 carbon. This densification provides a structural explanation for the observed improvement in mechanical performance of the secondary wall of flax fibres during the field retting process.
\end{abstract}

Keywords:

Flax fibres

Retting

Atomic force microscopy

X-ray diffraction

Mechanical properties

Solid-state

Nuclear magnetic resonance

\section{Introduction}

Flax (Linum Usitatissimum L.) is probably one of the oldest fibre plants used by humans, especially by the prehistoric cultures of Europe, but also in Egypt, ancient Babylonia, Palestine and along the shores of the Black Sea (Heer, 1873). Wild flax fibres have been identified in the ruins of the oldest Neolithic lacustrine villages in Switzerland, while 30,000-year-old flax fibres have been discovered in Upper Palaeolithic layers in Georgia (Kvavadze et al., 2009). Thus, prehistoric huntergatherers used flax fibres to manufacture cords for hafting stone tools, baskets and clothing. To extract fibres and separate them from the woody part of the stem, ancient civilisations developed water retting which is one of the oldest known bioprocesses. A first description of the retting stage can be found in the Sumerian poem, The Bridal Sheet (Poem, 3000BC), and archaeological discoveries indicate that this process was carried out at various places and periods in Antiquity.

Over the last few years, flax fibres have demonstrated their great potential as reinforcements of composite materials and their use is developing in several industrial domains, particularly in the transport sector (Witayakran, Smitthipong, Wangpradid, Chollakup, \& Clouston, 2017). Nevertheless, the need for ever-increasing productivity and the problem of storage leads to new consideration about the control and industrialization of the retting process. Indeed, this bioprocess often takes place under very different environmental conditions from one year to another, and its effects on the cell wall ultrastructure and fibre performance are poorly known. During retting, the various microorganisms present in the soil, due to environmental conditions and in particular the alternation of rain, dew and sun, colonize the flax stems (Djemiel, Grec, \& Hawkins, 2017; Sharma, Faughey, \& McDall, 1996). The enzymes they secrete, in particular polygalacturonases and xylanases, gradually degrade the pectic compounds mainly located in the middle lamellae of the fibre bundles but also in the interfacial areas with the cortical parenchyma or xylem. This damage to the plant tissues structure facilitates the extraction the fibre bundles during the scutching stage. The fibre bundles are also easier to separate (Akin, Foulk, Dodd, McAlister, \& McAlister, 2001), which favours good composite mechanical properties due to the improved fibre individualization and the reduction in the number of bundles (Coroller et al., 2013). Sharma (Sharma, 1988) showed that the limiting factor of retting is the degradation of homogalacturonans, in particular when these constituents are located in the epidermis; over-retting results in the loss of the cellulose that makes up the fibres (Placet, Day, \& Beaugrand, 2017),

\footnotetext{
* Corresponding author.

E-mail address: alain.bourmaud@univ-ubs.fr (A. Bourmaud).
} 


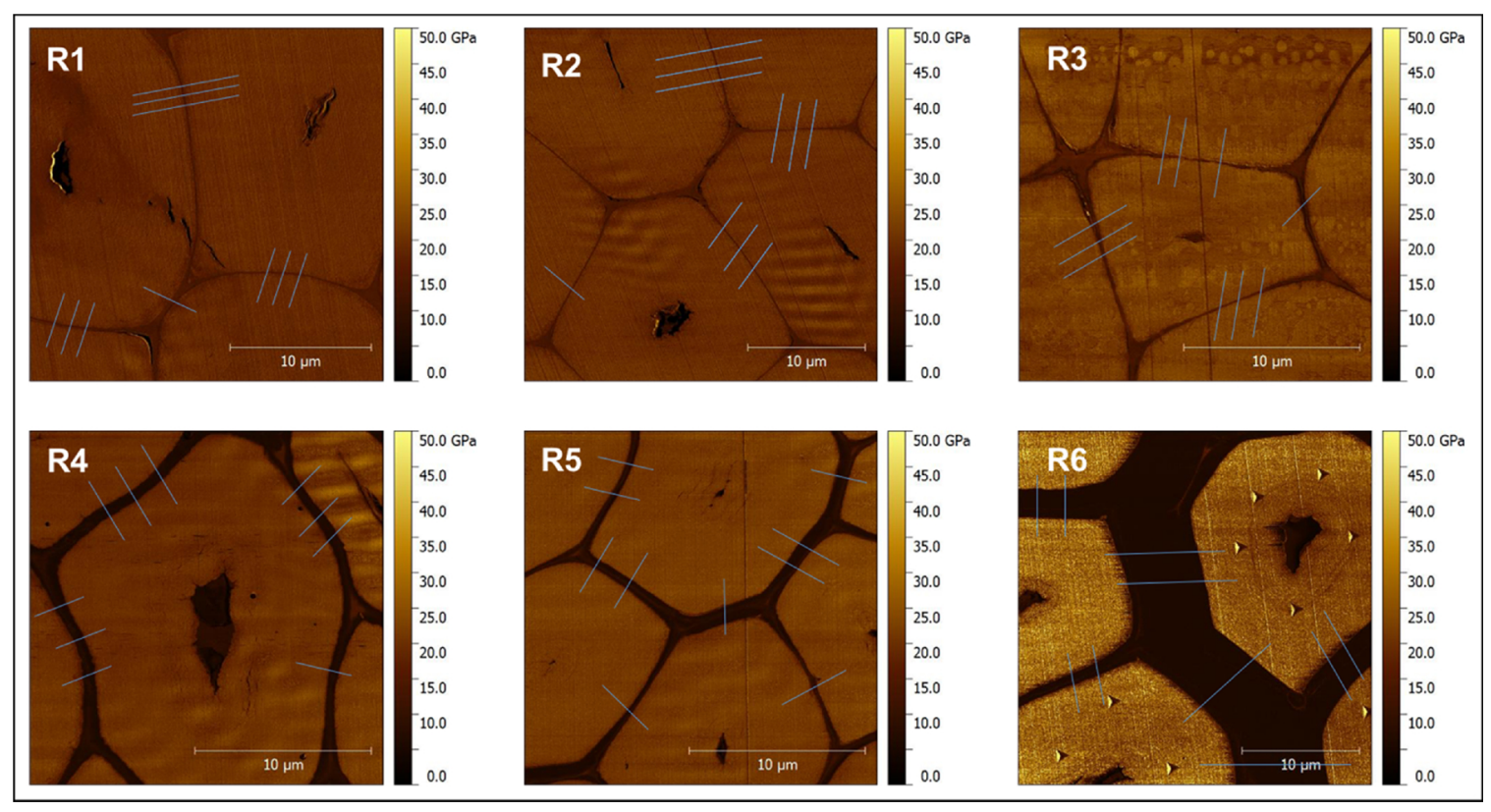

Fig. 1. AFM PF-QNM modulus mapping from R1 to R6 retting degree. The blue lines correspond to the direction and position where the thickness of the interfaces between fibres were measured (For interpretation of the references to colour in this figure legend, the reader is referred to the web version of this article).

arguably due to the well-known secretion of a second type of enzyme (cellulase).

Although the impact of retting on the properties and performances of plant fibres has already been investigated, the conclusions of these studies are unfortunately somewhat contradictory. Van de Weyenberg et al. (2003) obtained similar mechanical properties for fibre bundles of green, half-retted and retted flax, with stresses at break of 68.9, 72.8 and $71 \mathrm{cN} \cdot \mathrm{tex}^{-1}$, respectively, which indicate no significant change in performances. The same trend was highlighted by Alix et al. (2012)). By contrast, other authors (Martin, Mouret, Davies, \& Baley, 2013; Van de Velde \& Baetens, 2001) have measured higher tensile strength at break and Young's modulus values for the most retted single flax fibres.

The aim of the present study is to explore the evolution of the flax cell wall behaviour during a controlled dew retting phase. Structural and mechanical investigations were conducted at the cell wall scale using X-Ray Diffraction (XRD) and solid-state Nuclear Magnetic Resonance (NMR), while nanomechanical measurements were performed through nanoindentation and AFM Peak Force Quantitative Nano-Mechanical property mapping (AFM PF-QNM).

\section{Materials and methods}

\subsection{Flax fibres}

Flax plants of the Alizée variety were grown in France (Hauts-deFrance region) in 2011 and were provided by Van Robaeys Frères ${ }^{\circledR}$ (Killem, France); they were carefully stored at controlled humidity and temperature $\left(48 \% \mathrm{RH}\right.$ and $\left.23^{\circ} \mathrm{C}\right)$. Fibres samples are labelled R1, R2, R3, R4, R5 and R6, which corresponds to retting times of 1, 5, 9, 14, 16 and 19 days, respectively. Flax stems were pulled at the end of June and dew-retted in the field for different durations. Additional information about cultivation and climatic conditions are provided in (Martin et al., 2013).

\subsection{Sample embedding preparation}

A series of ethanol/deionized water concentration (50\%, 75\%, $90 \%$ and $100 \%$ ) were used to dehydrate samples. After this step, to maintain the fibre and the cell-wall structure during surface preparation, samples were embedded in a mixture containing increasing proportions of LR
(London Resin) White acrylic resin/ethanol (25\%, 50\%, 75\% and $100 \%)$. Then, the polymerization of the resin was finalised in an oven at $60{ }^{\circ} \mathrm{C}$ for one night. The aramid fibres were introduced into an epoxy resin (Struers Epofix) for $24 \mathrm{~h}$ and polymerization took place at room temperature. To obtain reliable measurements with the atomic force microscope, we must minimize their roughness at the nanometer scale. Consequently, the samples were prepared using an ultramicrotome (Leica Ultracut $\mathrm{R}$ ) with two consecutive diamond knives (Diatome Histo and Ultra AFM), to cut very thin sections (about $50 \mathrm{~nm}$ ) at low cutting speed $(\approx 1 \mathrm{~mm} / \mathrm{s})$ and thus reduce sample deformations.

\subsection{Nanoindentation and AFM peak force QNM measurements}

A commercial nanoindentation system Nanoindenteur XP (MTS Nano Instruments) was used at room temperature. All the samples were tested by using a Berkovich indenter (three-side pyramid), with a maximum depth of $150 \mathrm{~nm}$ (loading rate of $0.05 \mathrm{~s}^{-1}$ (i.e., $1 \mu \mathrm{N} / \mathrm{s}$ )). When the maximum load was reached, a holding segment of $20 \mathrm{~s}$ was performed before unloading (unloading rate of $10 \mu \mathrm{N} / \mathrm{s}$ ), followed by a thermal drift correction. The indentation modulus was calculated using the approach of Oliver and Pharr (Oliver \& Pharr, 1992); the values reported here are equal to the means of measurements obtained over at least 30 valid indentation locations.

Mechanical mapping of the sample surfaces was performed with a Multimode AFM instrument (Bruker Corporation, USA) by using the PFQNM imaging mode. In this mode, the vertical motion was set at a frequency of $2 \mathrm{kHz}$ (well below the cantilever resonance frequency, around $525 \mathrm{kHz}$ ). Mechanical property mapping was carried out using a RTESPA-525 (Bruker) probe with a cantilever spring constant around $140 \mathrm{~N} / \mathrm{m}$. Due to its high value, this cantilever stiffness was calibrated using the Sader method (Sader et al., 2012), as well as Scanning Electron Microscope (Jeol JSM $6460 \mathrm{~L} \mathrm{~V}$ ) images for the measurements of the cantilever dimensions (i.e., length and width). The tip radius, around $30 \mathrm{~nm}$, was adjusted on a Highly Oriented Pyrolytic Graphite (HOPG) reference sample, providing an indentation modulus of around $18 \mathrm{GPa}$. For all the measurements, the applied force was set at $200 \mathrm{nN}$ and the curves obtained were adjusted by a DMT contact model which takes into account the adhesion force (Barthel, 2008).

Undulations or waves are sometimes visible on the mechanical mapping images obtained (Fig. 1). This is due to the preparation of the 
surface with the microtome. This is a consequence of the AFM laser and its reflection on the samples surface, which causes interferences, especially here as the sample surface reflection quality is high due to its preparation. These interferences induce a bias, especially in the measurement of the adhesion force (Kassies, 2004; Méndez-Vilas, GonzálezMartín, \& Nuevo, 2002). In our case, for some measurements, nothing could be done to reduce or remove them, but the way we analysed the data reduces their effect on the values $r$ eported here. The c ell wall stiffness distribution was inferred by a djusting, with a Gaussian distribution (OriginPro 2017 software), the height distribution function (Gwyddion 2.39 software) calculated from the indentation modulus maps. This fitted Gaussian distribution yields the mean value (equal to the value at the maximum of the distribution here as this latter is symmetric) and the standard deviation of the indentation modulus.

Finally, these images are used to determine the thickness of the interface between fibres. This procedure is c arried o ut a long almost three lines per interface as shown in Fig. 1. These interfaces are initially composed of middle lamellae, but these are gradually replaced by embedding resin during progression of the retting process.

\section{4. $X$-ray diffraction}

Flax fibre bundles (diameter $\sim 150 \mu \mathrm{m}$ ) were extracted from plants and mounted on a Bruker-AXS D8 Discover diffractometer (Karlsruhe, Germany). $\mathrm{Cu} \mathrm{K} \alpha_{1}$ radiation ( $\lambda=1.5405 \AA$ ), generated in a sealed tube at $40 \mathrm{kV}$ and $40 \mathrm{~mA}$, was parallelized using a Gobël mirror parallel optics system and collimated to produce a $500 \mu \mathrm{m}$ incident beam diameter. Diffraction patterns were obtained by recording scans $(10 \mathrm{~min}$ for each sample) in the $2 \theta$ angle range between $10^{\circ}$ and $35^{\circ}$. The cellulose crystallinity index $\left(I_{\mathrm{c}}\right)$ of the fibre bundle was calculated using the common method described by Segal et al. (Segal, Creely, Martin, \& Conrad, 1959).

\subsection{NMR investigations}

First, the flax s amples w ere hydrated $\mathrm{w}$ ith $40 \% \mathrm{w}$ ater $(\mathrm{w} / \mathrm{w})$ in order to improve the spectral resolution. Solid state ${ }^{1} \mathrm{H} /{ }^{13} \mathrm{C} C \mathrm{CP} / \mathrm{MAS}$ NMR experiments were performed on a Bruker Avance III $400 \mathrm{MHz}$ spectrometer with a ${ }^{13} \mathrm{C}$ frequency of $100.62 \mathrm{MHz}$ by using a double resonance $\mathrm{H} / \mathrm{X} \mathrm{CP} / \mathrm{MAS} 4 \mathrm{~mm}$ probe. The samples were spun at room temperature and at a rate of $9 \mathrm{kHz}$. The cross-polarisation pulse sequence parameters were as follows: $3.0 \mu$ s proton $90^{\circ}$ pulse, $1.75 \mathrm{~ms}$ contact time at $37 \mathrm{kHz}$ and $10 \mathrm{~s}$ recycle time. Results were obtained after the accumulation of 5120 scans. The chemical shift of the ${ }^{13} \mathrm{C}$ NMR spectra was calibrated thanks to the use of the carbonyl signal of glycine (176.03 ppm), which was used as an external standard. All data were processed using Gaussian multiplication parameters of $\mathrm{LB}=$ $-20 \mathrm{~Hz}$ and $\mathrm{GB}=0.05$ and then Fourier transform was performed.

The approach of Larsson \& al. (Larsson, Wickholm, \& Iversen, 1997) was used to determine the cellulose crystallinity from the peak deconvolution of the C4 region (77-92 ppm. In the crystalline region the Larsson \& al. approach is performed thanks to the use of three Lorentzian peaks corresponding to cellulose $\mathrm{Cr}\left(\mathrm{I}_{\alpha}\right)(89.4 \mathrm{ppm})$, cellulose $\mathrm{Cr}$ $\left(\mathrm{I}_{\alpha+\beta}\right)(88.7 \mathrm{ppm})$ and cellulose $\mathrm{Cr}\left(\mathrm{I}_{\beta}\right)(87.7-87.8 \mathrm{ppm})$. In addition, an additional Gaussian peak representing the para-crystalline $(\mathrm{PCr})$ contribution (88.5-88.6 ppm) is used. Three others peaks were exploited in the amorphous region, two Gaussian peaks corresponding to the accessible surface (AS; 83.2 and 84.1-84.2 ppm) and another one for the inaccessible surface (IAS; 83.5-83.7 ppm).

The chemical shift, peak half-width and peak area of the different peaks were determined with a least squares fitting m ethod using Peakfit $^{\circledR}$ software. The cellulose cell wall crystallinity rate was calculated by dividing the area of the four peaks of the crystalline region by those of the seven peaks for the cellulose $\mathrm{C} 4$ region. The lateral dimensions of the fibrils (LFD) and the lateral dimensions of the fibril aggregates (FLAD) were then estimated using a square model of a cross- section of cellulose microfibril. This work is based on the total cellulosic surfaces of amorphous cellulose and a microfibril model with cellulosic chains $0.57 \mathrm{~nm}$ wide (Newman, 1999). Finally, CP/MAS ${ }^{13} \mathrm{C}$ variable contact time (VCT) spectroscopy was used to characterize the molecular dynamics of the samples. Twenty CP/MAS spectra were acquired using contact times from $10 \mu \mathrm{s}$ to $9 \mathrm{~ms}$, and accumulation of 920 scans for each spectrum. We then used a two-proton reservoir model (Kolodziejski \& Klinowski, 2002; Paris, Bizot, Emery, Buzaré, \& Buléon, 2001) to follow the evolution of carbon peak areas as a function of contact time.

\subsection{Statistical analysis}

The mean values of the indentation modulus of the different batches were evaluated in terms of statistical difference. A bilateral $t$-test with a $95 \%$ confidence interval was used and the value of the P-parameter was determined. When it is less than 0.05 , the difference between two batches is statistically significant.

\subsection{SEM analysis}

A Jeol JSM $6460 \mathrm{LV}$ scanning electron microscope was used to analyze the surface of the fibre bundles corresponding to the different degrees of retting. After being cut into $5 \mathrm{~mm}$ pieces, the flax fibre bundles were glued to a sample holder using a conductive adhesive. They were then metallized with a thin layer of gold using an Edwards Scancoat Six device during $180 \mathrm{~s}$.

\section{Results and discussion}

\subsection{Use of AFM PF-QNM and nanoindentation to explore structure and indentation modulus of flax cell walls}

For all levels of retting, AFM PF-QNM modulus mapping (Fig. 1) reveals a homogenous indentation modulus across the flax cell walls without any gradient (Goudenhooft et al., 2018), indicating the maturity of the bast flax fibres, even for the R1 level obtained at the pulling-out stage.

Fig. 2 shows the evolution of indentation modulus obtained by both AFM PF-QNM and nanoindentation tests. Here, nanoindentation is used to validate the AFM PF-QNM mechanical measurements; we note a good correlation between the two sets of data, with the same general tendency despite an underestimation of the indentation modulus (Arnould \& Arinero, 2015). AFM PF-QNM and nanoindentation measurements were not performed on the same fibre, which could lead to slight differences in stiffness values due to the natural character of flax cell walls.

To compare the indentation modulus values with literature data, it is appropriate to consider measurements on the R6 batch, corresponding to conventional retting before scutching. For this sample, nanoindentation and AFM PF-QNM indentation moduli are $19.3 \pm 3.8 \mathrm{GPa}$ and $17.2 \pm 1.5 \mathrm{GPa}$, respectively, which is in good agreement with previous measurements on mature and dew-retted flax cell walls (Alix et al., 2012). The indentation moduli are of the same order of magnitude as values obtained on the mature G-layer (Goudenhooft et al., 2018); in addition, the non-mature Gn-layer cannot be distinguished through AFM PF-QNM investigations (Fig. 1), demonstrating that the fibres are well-matured. Interestingly, we find a significant increase of the indentation modulus with retting level. Differences between R1 and R6 are $+17 \%$ and $+23 \%$ with AFM PF-QNM and nanoindentation measurements, respectively; to the authors' best knowledge, this stiffening has never been demonstrated at the cell wall scale. This increasing tendency is confirmed by the $t$-test statistical analysis, shown in Table 1. Sample sets were compared in pairs and values found to be statistically significant $(P<0.05)$, excepting the values comparing R2 to R4 and R3 to R5. 


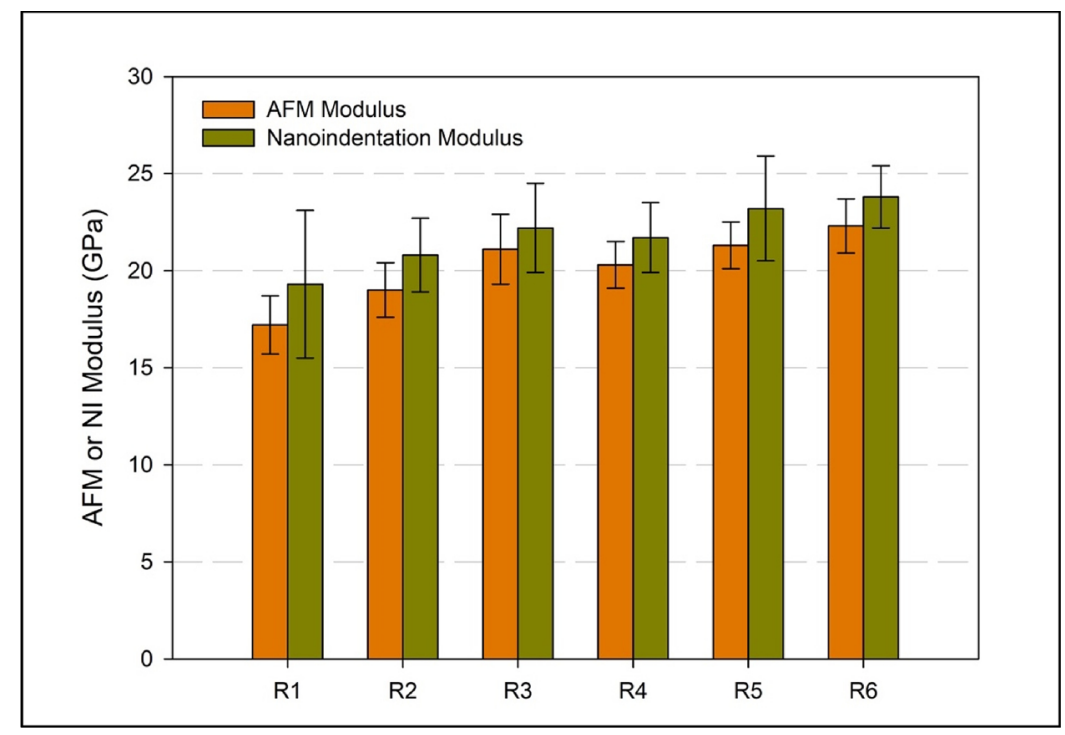

Fig. 2. Evolution of AFM and nanoindentation modulus of flax cell walls with the retting degree.

Table 1

Statistical analysis with $t$-test. P values are indicated for each couple of samples. Samples are assumed to be statistically different when $\mathrm{P}<0.05$. Values in red indicate that samples are statistically similar.

\begin{tabular}{lllllll}
\hline & $\mathrm{R} 1$ & $\mathrm{R} 2$ & $\mathrm{R} 3$ & $\mathrm{R} 4$ & $\mathrm{R} 5$ & $\mathrm{R} 6$ \\
\hline $\mathrm{R} 1$ & - & - & - & - & - & - \\
$\mathrm{R} 2$ & 0.00006 & - & - & - & - & - \\
R3 & 0.00000 & 0.00025 & - & - & - & - \\
R4 & 0.00001 & 0.25199 & 0.03050 & - & - & - \\
R5 & 0.00000 & 0.00053 & 0.39222 & 0.01355 & - & - \\
R6 & 0.00000 & 0.00000 & 0.00000 & 0.00000 & 0.00000 & - \\
\hline
\end{tabular}

However, some similar results have been obtained on the same fibre batches in another study focused on the tensile characterization of single flax fibres (Martin et al., 2013). In this latter study, the Young's modulus of the fibre was shown to increase by $+44 \%$ between levels R1 and R6. The increase difference between Young's modulus and indentation modulus is due to the anisotropic nature of the cell wall (Eder et al., 2013) and the difference in the investigation scale (i.e., whole fibre for the tensile test compared to local measurements at the cell wall scale in the present study). Therefore, there is a significant evolution of the overall fibre and cell wall stiffness during the retting process, evidenced by both tensile tests; nanoindentation and AFM. Although
Martin et al. (Martin et al., 2013) did not conduct a structural investigation, these authors used TGA analysis and hot-water/EDTA extraction to show a decrease in cortical parenchyma and middle lamella components, which is consistent with a dew-retting process. Similar conclusions were obtained for hemp fibres by Placet et al. (Placet et al., 2017), who found a significant decrease of pectic components. Moreover, these latter authors observed a decrease of xylan component which plays a determining role in the cell wall architecture and could potentially be linked to changes in the stiffness of the cell wall. According to these authors, this major structural evolution is linked to the worsened mechanical performance of single fibres, demonstrating that the tested hemp batch was over-retted and exposed to a profound, and therefore detrimental, enzyme degradation. These authors also highlight the great uncertainty in monitoring hemp retting compared to flax cultivation. In the latter case, exogenous parameters such as temperature are constantly checked by calculating accumulated temperature data (Lefeuvre, Bourmaud, Morvan, \& Baley, 2014). In view of these considerations, we can exclude over-retting in the present case and the positive evolution of cell wall mechanical properties should be linked rather to a change in the cell wall ultrastructure or conformation, such as an evolution of the cellulose crystallinity. These points are explored further below.

AFM PF-QNM investigations also provide interesting information about the bundle structure of scutched fibres during the retting process.

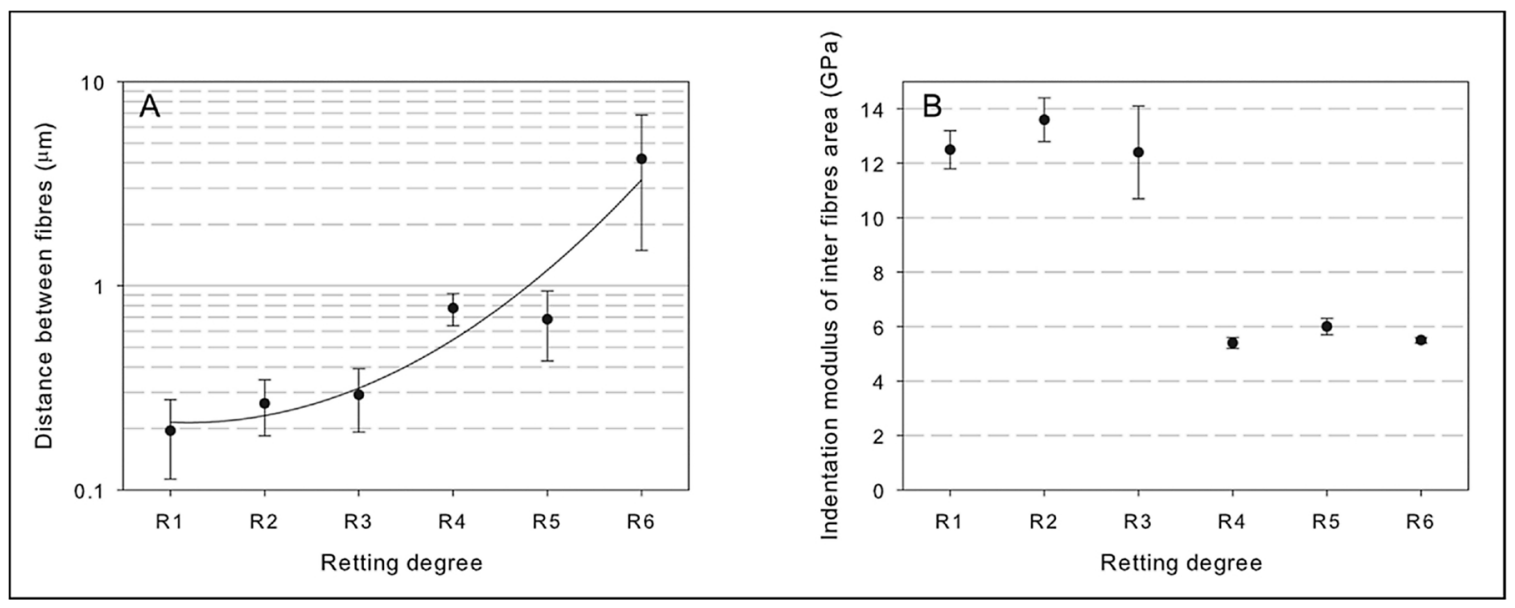

Fig. 3. Evolution of the distance (A) and indentation modulus (B) between scutched fibres along the retting process. 


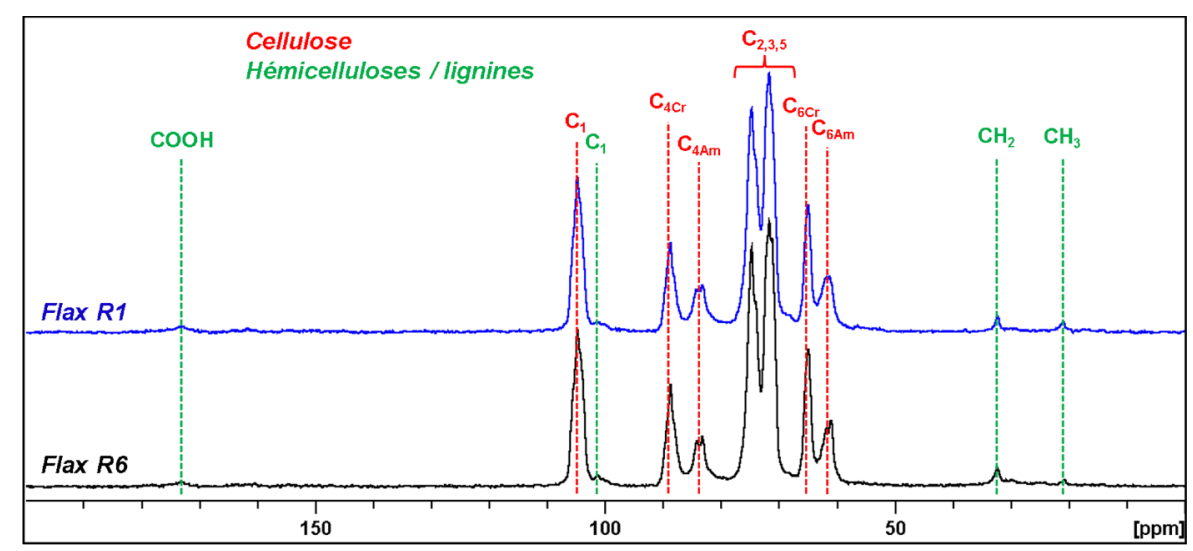

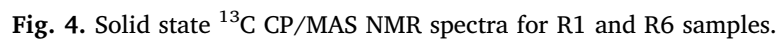

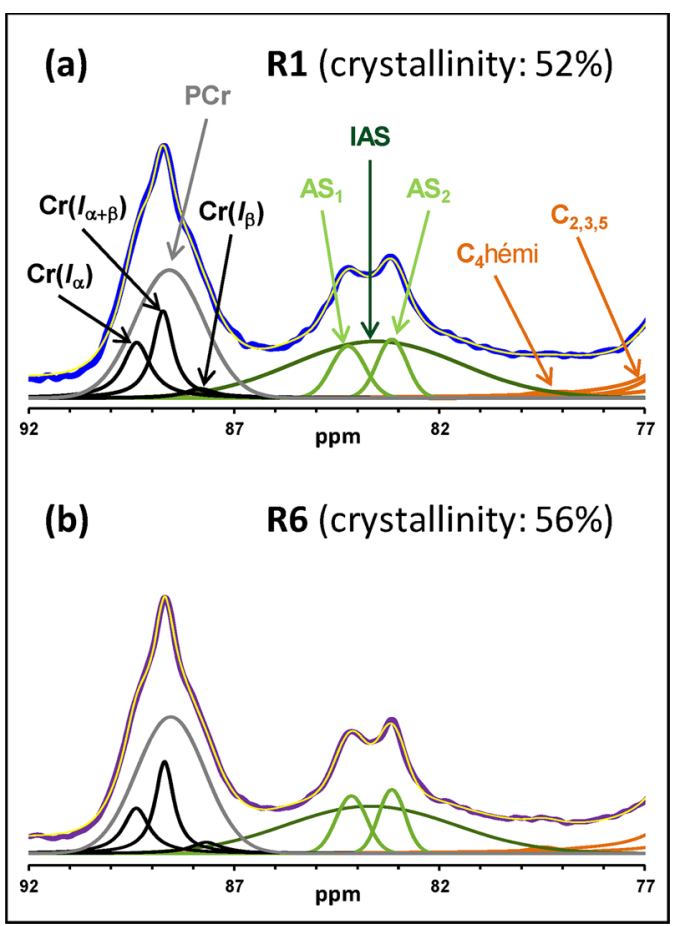

Fig. 5. Deconvolution of $\mathrm{C} 4$ region with crystalline forms $\mathrm{Cr}\left(\mathrm{I}_{\alpha}\right), \mathrm{Cr}\left(\mathrm{I}_{\beta}\right)$ and $\mathrm{Cr}$ $\left(\mathrm{I}_{\alpha+\beta}\right)$ (black), para-crystalline form (PCr) (grey), accessible fibril surfaces (AS) (green), and inaccessible fibril surface (IAS) (dark green) signals for R1 (a) and R6 (b) samples (For interpretation of the references to colour in this figure legend, the reader is referred to the web version of this article).

As shown in Fig. 1, the middle lamella is clearly visible for the first three retting levels (R1-R3) and appears to be cohesive with the surrounding fibres, especially at the junctions between fibres; with the increase of retting level and development of enzyme action, this middle lamella progressively disappears until it represents only a few fragments, as in the case of the R4 sample where it is still present but not physically linked with the primary wall of the fibre. At the same time, the inter-fibre space is filled with embedding resin, indirectly showing the importance of retting for enhancing the composite impregnation. Fig. 3.A illustrates the qualitative evolution of the thickness of the interface between fibres (i.e., middle lamella and/or embedding resin, see measurement lines in Fig. 1) throughout the retting process and the impact on fibre divisibility. Distance values correspond to the average interface length between fibres calculated from ten profile measurements represented by blue lines on Fig. 1 .

These observations are supported by additional mechanical investigations (Fig. 3B) In fact, local measurements performed by AFM
Table 2

Calculated parameters obtained from the $\mathrm{C} 4$ region deconvolution of ${ }^{13} \mathrm{C} \mathrm{CP} /$ MAS spectra for R1 and R6 samples. $\delta=$ chemical shift, FWHH $=$ Full Width at Half Height.

\begin{tabular}{|c|c|c|c|c|c|c|c|c|}
\hline & \multicolumn{7}{|c|}{ Peak assignment } & \\
\hline & $\operatorname{Cr}(\mathrm{I} \alpha)$ & $\operatorname{Cr}(\operatorname{I} \alpha+\beta)$ & $\mathrm{PCr}$ & $\operatorname{Cr}(\mathrm{I} \beta)$ & AS & IAS & AS & \\
\hline $\mathrm{R} 1$ & 89.37 & 88.73 & 88.58 & 87.83 & 84.22 & 83.53 & 83.16 & \multirow[t]{2}{*}{$\delta(\mathrm{ppm})$} \\
\hline R6 & 89.38 & 88.70 & 88.54 & 87.68 & 84.14 & 83.68 & 83.16 & \\
\hline $\mathrm{R} 1$ & 81 & 60 & 199 & 90 & 98 & 482 & 86 & \multirow[t]{2}{*}{ FWHH (Hz) } \\
\hline R6 & 76 & 55 & 197 & 90 & 88 & 484 & 76 & \\
\hline $\mathrm{R} 1$ & 8 & 10 & 32 & 2 & 6 & 35 & 7 & \multirow{2}{*}{$\begin{array}{l}\text { Normalized } \\
\text { area }(\%)\end{array}$} \\
\hline R6 & 7 & 10 & 37 & 2 & 7 & 31 & 7 & \\
\hline
\end{tabular}

PF-QNM in the middle lamella region yield indentation moduli of $12.5 \pm 0.7 \mathrm{GPa}, 13.6 \pm 0.8 \mathrm{GPa}$ and $12.4 \pm 1.7 \mathrm{GPa}$, for R1, R2 and R3 samples, respectively. On the other hand, similar investigations carried out on the most retted samples (R4, R5 and R6) give results between $5.4 \pm 0.2 \mathrm{GPa}$ and $6.0 \pm 0.3 \mathrm{GPa}$, which correspond to the resin indentation modulus. The resin indentation modulus is slightly higher here than the literature value (Goudenhooft et al., 2018), presumably due to the presence of a residual middle lamella fraction in the inter-fibre space, especially in R4 and R5 samples. Values obtained in the middle lamella region are slightly higher than those reported in the literature for wood by nanoindentation in the cell corner middle lamella (Gindl, Schoberl, \& Schöberl, 2004). A better knowledge of the middle lamellae is of great interest here, especially to highlight their cohesive function in fibres bundles; nevertheless, these data must be considered with caution, being only of relative value to compare cell wall indentation moduli, and should not be used, for example, to establish an absolute value of the longitudinal Young's modulus in numerical or micromechanical modelling.

\subsection{Monitoring of crystallinity degree during retting using $X$-ray diffraction and NMR analysis}

In the literature, an increase in the crystallinity of plant fibres during retting has been demonstrated from crystallinity index measurements obtained by X-Ray diffraction. Zafeiropoulos, Baillie, and Matthews (2001) report an increase of the crystallinity index from $64.55 \%$ for green flax to $71.64 \%$ for dew retted flax. Moreover, Marrot, Lefeuvre, Pontoire, Bourmaud, \& Baley (2013) report an increase in the degree of crystallinity of hemp fibres following the retting of the plant in the field. The crystallinity index increased from $45.8 \%$ for green hemp, to $71.3 \%, 71.2 \%$ and $74.5 \%$ after 14,31 and 45 days of ground retting, respectively.

In the present case, the cell wall cellulose crystallinity of R1 and R6 


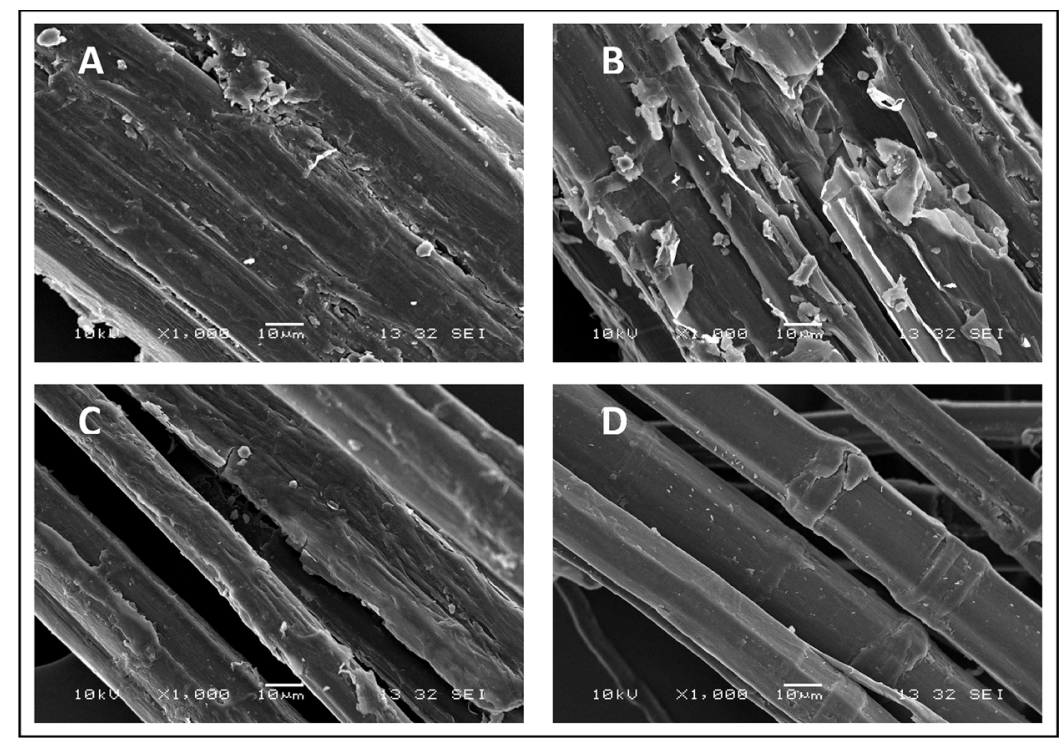

Fig. 6. SEM images of R1, R3, R4 and R6 samples.

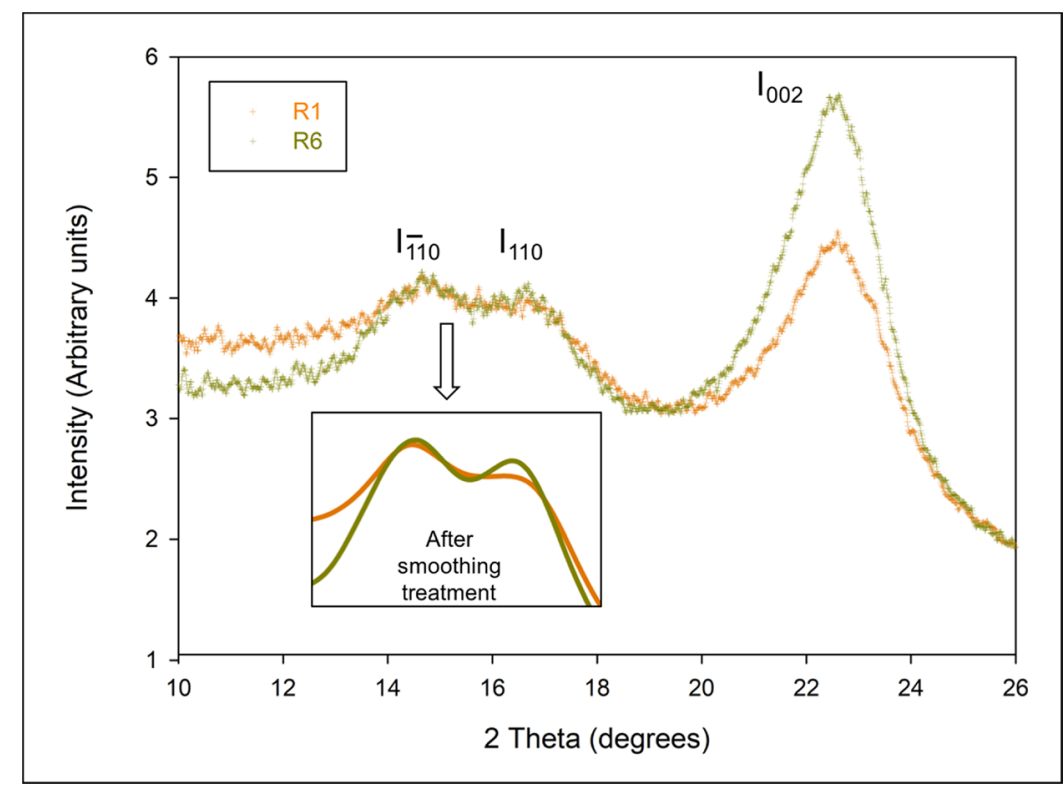

Fig. 7. X-Ray Diffraction patterns of R1 and R6 flax samples.

was investigated by both NMR and XRD. We chose to focus only on retting levels R1 and R6; the important variations in mechanical properties lead us to focus on these two extreme cases. Fig. 4 shows the ${ }^{13} \mathrm{C}$ CP/MAS NMR spectra obtained for R1 and R6 samples. These spectra are characteristic of type-I cellulose (Dinand, Vignon, Chanzy, \& Heux, 2002) for the two samples studied. Characteristic hemicelluloses signals are also observed as part of the main constituents of flax plant cell walls. To obtain information on the supramolecular structure of cellulose fibrils in the plant cell walls, the C4 region between 77 and $92 \mathrm{ppm}$ is deconvoluted here using the model of Larsson et al. (1997).

Fig. 5 illustrates this deconvolution, while Table 2 reports the peak assignments with their corresponding values of full width at half height (FWHH) and normalized areas. The crystallinity appears higher for the R6 sample (56\%) than for the R1 sample (52\%), a slight but significant difference, see (Villares et al., 2017). Although the NMR-derived crystallinity values are lower than those obtained by XRD, the observed trend is in line with the measurements already available on non-retted and retted flax or hemp fibres. These literature measurements were carried out using XRD on fibre bundles, which can make their interpretation more complex. Indeed, during the data processing of bundles, the signal corresponding to the amorphous constituents can be influenced by components outside the cell walls, in particular the residues of middle lamellae which may be present, especially for samples with a low retting level, as shown in Fig. 6. In the case of NMR analysis, this problem does not arise, as the processing of data from C4 celluloserelated signals restricts the scope of investigation solely to the cell wall components.

To supplement the crystallinity data obtained by NMR, the XRD patterns of R1 and R6 samples are presented in Fig. 6. As usual for vegetal samples, we observe that the major crystalline peak occurs at around $22.4^{\circ}$, which corresponds to the crystallographic plane (002) representative of type- 1 cellulose. In the case of cellulose II conversion, new peaks attributed to (110) and (012) planes could be observed around $20^{\circ}$ (Ouajai \& Shanks, 2005), but are not present here. The crystallinity index (CI) is calculated according to the Segal method; although this method applies to bundles and not isolated fibres (Thygesen, Oddershede, Lilholt, Thomsen, \& Sta, 2005), it is suitable for obtaining rapid measurements and therefore abundant published data 


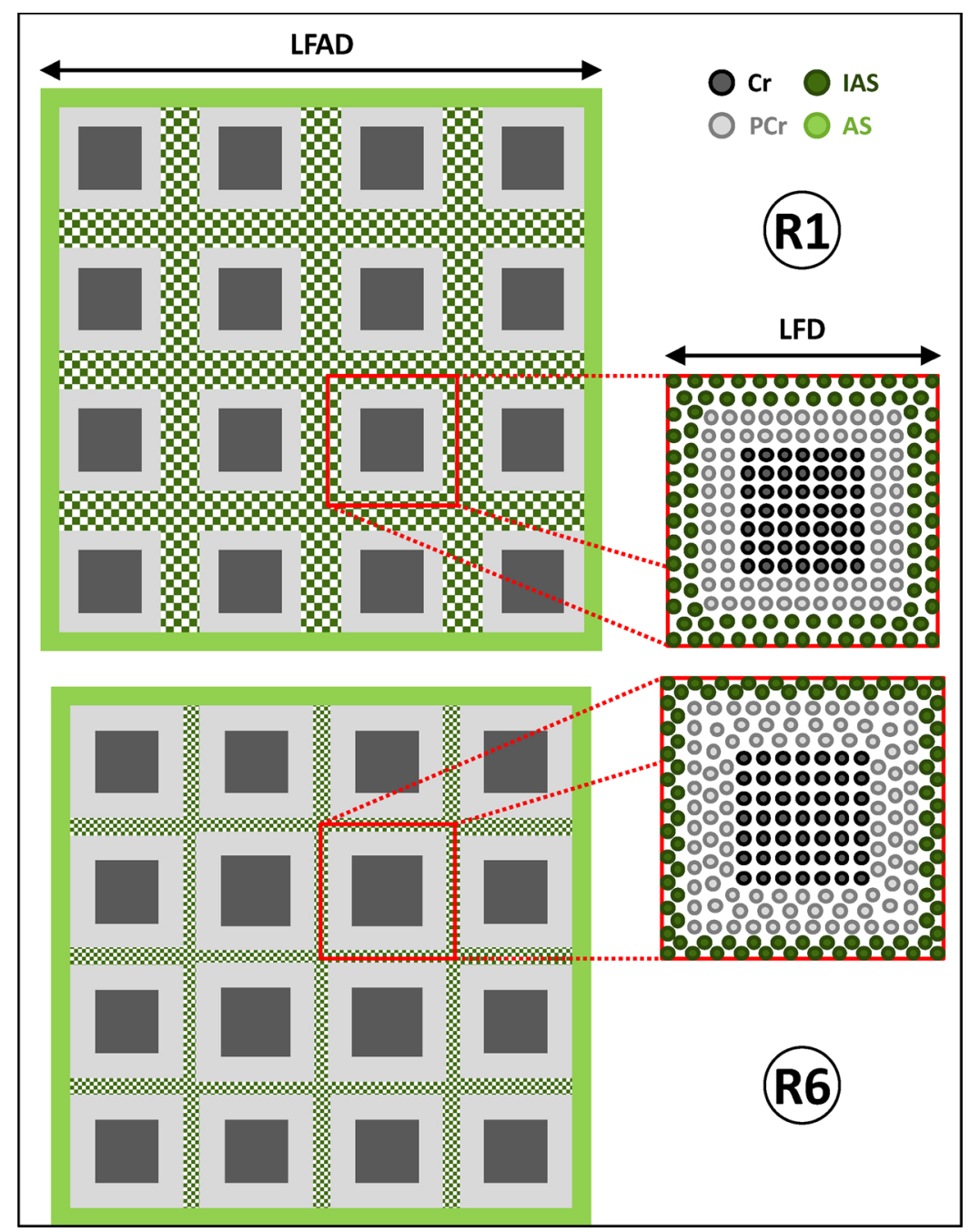

Fig. 8. Schematic representation of the flax cellulose elementary microfibrils structure. Cr: crystalline cellulose, PCr: paracrystalline cellulose, IAS: inaccessible surface, AS: accessible surface, LFD: lateral fibril dimension and LFAD: lateral fibril aggregate dimension. The surface areas (left part) and the number of points (zoomed views) in the scheme are proportional to the area of the corresponding NMR signals.

Table 3

Relaxation time values extracted from the two proton reservoir model (see text and Fig. 8) for the crystalline and amorphous C4 peaks areas of R1 and R6 samples.

\begin{tabular}{|c|c|c|c|c|c|c|}
\hline & \multicolumn{2}{|c|}{$\mathrm{T}_{1 \rho}^{H}(\mathrm{~ms})$} & \multicolumn{2}{|c|}{$\mathrm{T}_{\mathrm{CH}}(\mu \mathrm{s})$} & \multicolumn{2}{|c|}{$\mathrm{T}_{\mathrm{HH}}(\mu \mathrm{s})$} \\
\hline & R1 & R6 & R1 & R6 & R1 & R6 \\
\hline $\mathrm{C}_{4 \mathrm{cr}}$ & 19.3 & 34.7 & 15 & 16 & 687 & 947 \\
\hline $\mathrm{C}_{4 \mathrm{am}}$ & 14.7 & 23.0 & 15 & 16 & 501 & 772 \\
\hline
\end{tabular}

are available for purposes of comparison. Estimated CI for R1 and R6 are $31 \%$ and $44 \%$; thus, R1 exhibits a low CI compared to R6. As observed by NMR analysis, an increase of the $\mathrm{CI}$ is highlighted between $\mathrm{R} 1$ and R6 samples, but this latter is more pronounced by XRD analysis. This is probably due to the large amount of residual amorphous components remaining in the middle lamella areas and inducing an error into the calculation of CI, based on the ratio between crystalline and amorphous materials at the bundle scale. For this reason, the CI of R1 sample is probably underestimated. To check this hypothesis, it is possible to study the behaviour of the diffraction peaks at $2 \theta=14.8^{\circ}$ and $2 \theta=16.4^{\circ}$, corresponding to the (1) 0 and (110) crystallographic planes, respectively. The literature shows that these two peaks are more separated when the crystalline cellulose content of the sample is high
(Tserki et al., 2005). On the other hand, if the samples contain a significant quantity of amorphous constituents, attributable for flax fibres to pectins, lignin, hemicelluloses or amorphous parts of cellulose, these two peaks appear confused and more difficult to distinguish. The smoothing of this specific area (Fig. 6) confirms that the content of amorphous components is higher in the R1 sample.

\subsection{Investigation of cell wall biochemical structure using NMR}

Table 2 gives the detailed characteristics of the different peaks obtained after deconvolution of the NMR spectra presented in Fig. 4. Two main observations can be drawn from these data; firstly, the inaccessible surface of cellulose decreases significantly with retting, decreasing from 35 to $31 \%$ and, at the same time, the fraction of paracrystalline cellulose increases from 32 to $37 \%$. Paracrystalline cellulose is an intermediate form of cellulose, but which is considered as crystalline. It is noteworthy that, at the same time, the proportion of crystalline cellulose $(\mathrm{Cr})$ remains unchanged at $20 \%$ and $19 \%$, respectively, for R1 and R6. The same applies to the accessible surface, which remains constant (about 13\%) for both levels of retting. These data indicate that the inaccessible fraction of cellulose is the main component impacted by retting, representing a component evolving towards paracrystalline cellulose

Owing to this data set, it is possible to determine morphological 


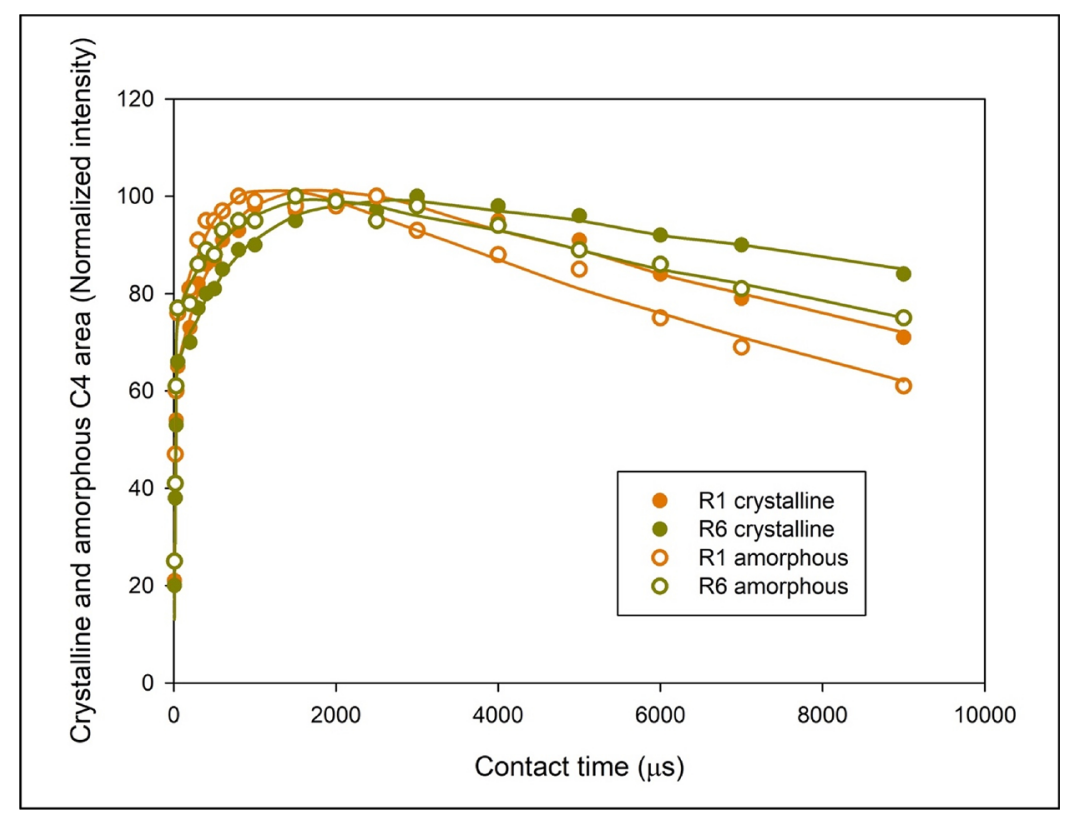

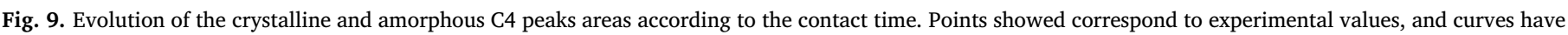
been obtained through the use of a two proton reservoir model (Kolodziejski \& Klinowski, 2002; Paris et al., 2001).

parameters related to the structure of cellulose and microfibrils. From the determination of crystallinity, we can estimate the LFD (Lateral Fibril Dimension) and the LFAD (Lateral Fibril Aggregate Dimension) according to the method of Zuckerstätter et al. (Zuckerstätter et al., 2009). The LFD of samples R1 and R6 are 4.1 and $4.5 \mathrm{~nm}$, respectively, while the LFAD slightly decreases during retting from $17.1 \mathrm{~nm}$ for R1 to $16.3 \mathrm{~nm}$ for R6. Fig. 7 gives a schematic representation of the flax cellulose elementary microfibrils that reflects the differences in structure highlighted by the solid NMR spectra. The basic pattern chosen here with 16 fibrils is compatible with the relative scale of the constituents, the aggregate being approximately 4 times larger than the elementary fibril.

As mentioned above, we observe a slight decrease in LFAD corresponding to a densification in aggregate size, which is well correlated with the decrease in inaccessible surface area (IAS). This is probably caused by a decrease in porosity (as illustrated in Fig. 7) within cell wall polymers, and consequently a compaction of cellulose within the walls in which the cellulose microfibrils are located. The flax cell walls evolve during their maturation, in particular with a transition from the Gn- to the G-layer. This phenomenon is assumed to result in a compaction of the cell walls under the action of galactosidases, responsible for the cutting of the long galactan chains which are then easily entrapped between the cellulose fibrils (Gorshkova et al., 2015; Goudenhooft et al., 2018). Even if this compaction occurs throughout plant growth, it is not excluded that maturation could be completed during the retting period. Thus, most of the cellulosic components in the R6 sample become truly isolated, being surrounded by densified layers of inaccessible surfaces (IAS). This does not apply in the case of degradation of surrounding layers, which could occur due to over retting (Placet et al., 2017) or prolonged thermal exposure (Van de Velde \& Baetens, 2001). The phenomenon of shrinkage described above can be linked to the increase of paracrystalline cellulose; in fact, under the effect of compression, a fraction of amorphous cellulose can evolve towards a paracrystalline form.

The last section of this NMR investigation involves using the twoproton reservoir model to study the evolution of the crystalline and amorphous C4 peaks areas as a function of the contact time. Fig. 8 shows the experimental data obtained for R1 and R6 samples along with model estimates. The associated relaxation time values are summarized in Table 3. We note higher values of $T_{1 \rho}^{H}$ for the R6 sample compared to R1. The increase of these values highlights a drop in the mobility which could be associated with a higher degree of molecular order. As shown on Fig. 8 and Table 3, the amorphous C4 yields lower values than crystalline forms and the increase in $T_{1 \rho}^{H}$ with retting is reduced, being $+56 \%$ instead of $+80 \%$ for crystalline C 4 . These results indicate that the amorphous components are probably more affected by retting than crystalline components. This suggested decrease in crystalline component mobility is consistent with the hypothesis of compaction of the inaccessible parts of the cell walls. Zhang et al. (Zhang, Wu, Haryono, \& Xia, 2014) have already shown that the increase in Young's modulus may be related to an increase in $T_{1 \rho}^{H}$. This hypothesis, combined with the densification of the walls, allows us to explain the evolution of the mechanical properties of the cell walls as highlighted by AFM PF-QNM (Fig. 9).

\section{Conclusion}

This study aims to improve our knowledge of ultrastructural phenomena at the cell wall scale occurring during the field retting of flax. Thus, we make use of AFM PF-QNM, X-RD and NMR techniques to investigate the mechanical and structural modifications during retting.

Determination of the cell wall indentation modulus by AFM PFQNM allows us to obtain both mechanical and morphological information; the results highlight a significant increase in the indentation modulus with retting time. Moreover, morphological analyses of the samples show a progressive increase in the distance between fibres associated with the disappearance of the middle lamellae, thus illustrating the progressive action of enzymes on the digestion of middle lamellae.

In addition, the degree of crystallinity is studied using both solidstate NMR and XRD. Indeed, these methods of analysis are quite different, as well as their scales of analysis. The global signal obtained on fibre bundles measured by XRD probably overestimates the differences in crystallinity between the retting states. Indeed, the calculation protocol is based on a comparison between amorphous and crystalline components, including the amorphous residues of middle lamellae whose abundance varies greatly between samples. Thus, the modest increase in crystallinity highlighted by NMR is probably more consistent with the physicochemical phenomena involved in retting at the cell wall scale. NMR results also show a significant evolution in the cell 
wall ultrastructure of flax during the retting stages. The improvement in the mechanical performance of plant cell walls can be explained by the compaction of inaccessible zones, combined with an increase in contact time, as demonstrated by modelling with the two-reservoir method showing a decrease in mobility. The original coupling of NMR and XRD for the analysis of ultrastructure provides a significant contribution to the understanding of the mechanisms involved in retting and represents a further step in optimizing the performance of flax fibres for use as reinforcements for composite materials.

\section{Acknowledgements}

The authors are grateful to Oseo, Region Bretagne and CNRS for funding this work. The authors acknowledge the BIBS platform of INRA Angers-Nantes for access to NMR facilities and L ucile Nuez and Anthony Magueresse for SEM images.

\section{References}

Akin, D. E., Foulk, J. A., Dodd, R. B., McAlister, D. D., \& McAlister, D. D., III (2001) Enzyme-retting of flax and characterization of processed fibers. Journal of BiotechnologyBiotechnology in the Textile Industry - Perspectives for the New Millennium, 89(2-3), 193-203. https://doi.org/10.1016/S0168-1656(01)00298-X.

Alix, S., Lebrun, L., Marais, S., Philippe, E., Bourmaud, A., Baley, C., et al. (2012). Pectinase treatments on technical fibres of flax: Effects on water sorption and mechanical properties. Carbohydrate Polymers, 87(1), 177-185. https://doi.org/10. 1016/j.carbpol.2011.07.035.

Arnould, O., \& Arinero, R. (2015). Towards a better understanding of wood cell wall characterisation with contact resonance atomic force microscopy. Composites Part A: Applied Science and Manufacturing, 74, 69-76.

Barthel, E. (2008). Adhesive elastic contacts: JKR and more. Journal of Physics D: Applied Physics, 41, 163001.

Coroller, G., Lefeuvre, A., Le Duigou, A., Bourmaud, A., Ausias, G., Gaudry, T., et al. (2013). Effect of flax fibres individualisation on tensile failure of flax/epoxy unidirectional composite. Composites Part A: Applied Science and Manufacturing, 51. https://doi.org/10.1016/j.compositesa.2013.03.018.

Dinand, E., Vignon, M., Chanzy, H., \& Heux, L. (2002). Mercerization of primary wall cellulose and its implication for the conversion of cellulose $\mathrm{I}\{\backslash$ textrightarrow $\}$ cellulose II. Cellulose, 9(1), 7-18. https://doi.org/10.1023/A:1015877021688.

Djemiel, C., Grec, S., \& Hawkins, S. (2017). Characterization of bacterial and fungal community dynamics by high-throughput sequencing (HTS) metabarcoding during flax dew-retting. Frontiers in Microbiology, 8, 2052. https://doi.org/10.3389/fmicb. 2017.02052.

Eder, M., Arnould, O., Dunlop, J. W. C., Hornatowska, J., Salmen, L., Salmén, L., \& Salmen, L. (2013). Experimental micromechanical characterisation of wood cell walls. Wood Science and Technology, 47, 163-182. https://doi.org/10.1007/s00226012-0515-6.

Gindl, W., Schoberl, T., \& Schöberl, T. (2004). The significance of the elastic modulus of wood cell walls obtained from nanoindentation measurements. Composites Part A: Applied Science and Manufacturing, 35(11), 1345-1349.

Gorshkova, T., Mokshina, N., Chernova, T., Ibragimova, N., Salnikov, V., Mikshina, P., et al. (2015). Aspen tension wood fibers contain $\beta$ - $(1 \rightarrow 4)$-galactans and acidic arabinogalactans retained by cellulose microfibrils in gelatinous walls. Plant Physiology, 169. https://doi.org/10.1104/pp.15.00690 2048-20.

Goudenhooft, C., Siniscalco, D., Arnould, O., Bourmaud, A., Sire, O., Gorshkova, T., et al. (2018). Investigation of the mechanical properties of flax cell walls during plant development: The relation between performance and cell wall structure. Fibers, 6(1), 6. https://doi.org/10.3390/fib6010006.

Heer, O. (1873). Prehistoric culture of flax. Nature, 453.

Kassies, R. (2004). Removing interference and optical feedback artifacts in atomic force microscopy measurements by application of high frequency laser current modulation. The Review of Scientific Instruments, 75(3), 689.

Kolodziejski, W., \& Klinowski, J. (2002). Kinetics of cross-polarization in solid-state NMR: A guide for chemists. Chemical Reviews, 102(3), 613-628. https://doi.org/10.1021/ cr000060n.

Kvavadze, E., Bar-Yosef, O., Belfer-Cohen, A., Boaretto, E., Jakeli, N., Matskevich, Z. et al. (2009). 30,000-year-old wild flax fibers. Science, 325(5946), 1359.

Larsson, P. T., Wickholm, K., \& Iversen, T. (1997). A CP/MAS13C NMR investigation of molecular ordering in celluloses. Carbohydrate Research, 302(1), 19-25. https://doi. org/10.1016/S0008-6215(97)00130-4.

Lefeuvre, A., Bourmaud, A., Morvan, C., \& Baley, C. (2014). Tensile properties of elementary fibres of flax and glass: Analysis of reproducibility and scattering. Materials Letters, 130(0), 289-291. https://doi.org/10.1016/j.matlet.2014.05.115.

Marrot, L., Lefeuvre, A., Pontoire, B., Bourmaud, A., \& Baley, C. (2013). Analysis of the hemp fiber mechanical properties and their scattering (Fedora 17). Industrial Crops and Products, 51(0), 317-327. https://doi.org/10.1016/j.indcrop.2013.09.026 Journal Article.

Martin, N., Mouret, N., Davies, P., \& Baley, C. (2013). Influence of the degree of retting of flax fibers on the tensile properties of single fibers and short fiber/polypropylene composites. Industrial Crops and Products, 49(0), 755-767. https://doi.org/10.1016/j. indcrop.2013.06.012.

Méndez-Vilas, A., González-Martín, M., \& Nuevo, M. (2002). Optical interference artifacts in contact atomic force microscopy images. Ultramicroscopy, 92(3-4), 243-250.

Newman, R. H. (1999). Estimation of the lateral dimensions of cellulose crystallites using C-13 NMR signal strengths. Solid State Nuclear Magnetic Resonance, 15, 21-29. https://doi.org/10.1016/s0926-2040(99)00043-0.

Oliver, W. C., \& Pharr, G. M. (1992). An improved technique for deterimining hardness and elastic modulus using load and displacement sensing indentation experiments. J. Mat. Res, 7, 1564-1583.

Ouajai, S., \& Shanks, R. A. (2005). Composition, structure and thermal degradation of hemp cellulose after chemical treatments. Polymer Degradation and Stability, 89(2), 327-335.

Paris, M., Bizot, H., Emery, J., Buzaré, J., \& Buléon, A. (2001). NMR local range investigations in amorphous starchy substrates: II-Dynamical heterogeneity probed by 1H/13C magnetization transfer and 2D WISE solid state NMR. International Journal of Biological Macromolecules, 29, 137-143 https://doi.org/S0141-8130(01)00161-1.

Placet, V., Day, A., \& Beaugrand, J. (2017). The influence of unintended field retting on the physicochemical and mechanical properties of industrial hemp bast fibres. Journal of Materials Science, 52(10), 5759-5777. https://doi.org/10.1007/s10853017-0811-5.

Poem, S. (3000BC). The Bridal Sheet. Translated by Jacobsen (1987), 13(15).

Sader, J. E., Sanelli, J. A., Adamson, B. D., Monty, J. P., Wei, X., Crawford, S. A., et al. (2012). Spring constant calibration of atomic force microscope cantilevers of arbitrary shape. The Review of Scientific Instruments, 83(10), 103705. https://doi.org/10. 1063/1.4757398.

Segal, L., Creely, J. J., Martin, A. E., \& Conrad, C. M. (1959). An empirical method for estimating the degree of crystallinity of native cellulose using the X-ray diffractometer. Textile Research Journal, 29(10), 786-794. https://doi.org/10.1177/ 004051755902901003.

Sharma, H. S. S. (1988). Chemical retting of flax using chelating compounds. The Annals of Applied Biology, 113(1), 159-165. https://doi.org/10.1111/j.1744-7348.1988. tb03292.x.

Sharma, H. S. S., Faughey, G., \& McDall, D. (1996). Effect of sample preparation and heating rate on the differential thermogravimetric analysis of flax fibres. Journal of Text Inst, 87(2), 249.

Thygesen, A., Oddershede, J., Lilholt, H., Thomsen, A., \& Sta, K. (2005). On the determination of crystallinity and cellulose content in plant fibres. Cellulose, 12, 563-576.

Tserki, V., Zafeiropoulos, N. E. F. S., Panayiotou, C., Zafeiropoulos, N. E., Simon, F., \& Panayiotou, C. (2005). A study of the effect of acetylation and propionylation surface treatments on natural fibres. Composites Part A: Applied Science and Manufacturing, 36(8), 1110-1118.

Van de Weyenberg, I., Ivens, J., De Coster, A., Kino, B., Baetens, E., \& Verpoest, I. (2003). Influence of processing and chemical treatment of flax fibres on their composites. Composites Science and Technology, 63(9), 1241-1246. https://doi.org/10.1016/ S0266-3538(03)00093-9.

Van de Velde, K., \& Baetens, E. (2001). Thermal and mechanical properties of flax fibres as potential composite reinforcement. Macromolecular Materials and Engineering, 286(6), 342-349. https://doi.org/10.1002/1439-2054(20010601)286:6<342::AIDMAME342 > 3.0.CO;2-P.

Villares, A., Moreau, C., Bennati-Granier, C., Garajova, S., Foucat, L., Falourd, X., et al. (2017). Lytic polysaccharide monooxygenases disrupt the cellulose fibers structure. Scientific Reports, 7, 40262-40270. https://doi.org/10.1038/srep40262.

Witayakran, S., Smitthipong, W., Wangpradid, R., Chollakup, R., \& Clouston, P. L. (2017). Natural fiber composites: Review of recent automotive trends. Reference Module in Materials Science and Materials Engineering. https://doi.org/10.1016/B978-0-12803581-8.04180-1.

Zafeiropoulos, N. E., Baillie, C. A., \& Matthews, F. L. (2001). A study of transcrystallinity and its effect on the interface in flax fibre reinforced composite materials. Composites Part A: Applied Science and Manufacturing, 32(3-4), 525-543. https://doi.org/10. 1016/S1359-835X(00)00058-0 Journal Article.

Zhang, X., Wu, X., Haryono, H., \& Xia, K. (2014). Natural polymer biocomposites produced from processing raw wood flour by severe shear deformation. Carbohydrate Polymers, 113, 46-52. https://doi.org/10.1016/j.carbpol.2014.06.076.

Zuckerstätter, G., Schild, G., Wollboldt, P., Röder, T., Weber, H., \& Sixta, H. (2009). The elucidation of cellulose supramolecular structure by 13C CP-MAS NMR, 87, Lenzinger Berichte38-46. 